\title{
Functional transepithelial transport measurements to detect nephrotoxicity in vitro using the RPTEC/TERT1 cell line
}

\author{
Philipp F. Secker ${ }^{1,2}\left[\right.$ [ Nadja Schlichenmaier ${ }^{1} \cdot$ Mario Beilmann $^{3} \cdot$ Ulrich Deschl $^{3} \cdot$ Daniel R. Dietrich $^{1}(0$
}

\begin{abstract}
The kidney is a frequent target for organ-specific toxicity as a result of its primary function in controlling body fluids, for example, via resorption of amino acids, peptides, nutrients, ions, xenobiotics and water from the primary urine as well as excretion of metabolic waste products and hydrophilic and amphiphilic xenobiotics. Compounds exhibiting dose-limiting nephrotoxicity include drugs from highly diverse classes and chemical structures, e.g., antibiotics (gentamicin), chemotherapeutics (cisplatin), immunosuppressants (cyclosporine A and tacrolimus) or bisphosphonates (zoledronate). All of these compounds elicit nephrotoxicity primarily by injuring renal proximal tubule epithelial cells (RPTECs). However, prediction of a compound's nephrotoxic potential in humans to support early unmasking of risk-bearing drug candidates remains an unmet challenge, mainly due to the complex kidney anatomy as well as pronounced inter- and intraspecies differences and lack of relevant and validated human in vitro models. Accordingly, we used the recently established human RPTEC/TERT1 cell line to carry out toxicity studies with a focus on impairment of functional characteristics, i.e., transepithelial electrical resistance (TEER), vectorial transport of water, cations, and anions. Results were compared to real-time cytotoxicity assessments using cellular impedance (xCELLigence assay) and the routine cell viability readout (MTT). As expected, most toxins caused exposure time- and concentration-dependent cytotoxicity. However, for some compounds (cyclosporine A and tacrolimus), transport processes were strongly impaired in absence of a concomitant decrease in cell viability. In conclusion, these data demonstrate that functional parameters are important, highly sensitive and meaningful additional readouts for nephrotoxicity assessment in human renal proximal tubule epithelial cells.
\end{abstract}

Keywords Kidney $\cdot$ Nephrotoxicity $\cdot$ Proximal tubule $\cdot$ In vitro $\cdot$ Epithelial transport

\section{Introduction}

The special vulnerability of the kidney is a result of its primary function in controlling body fluids, for example, via resorption of amino acids, peptides, nutrients, ions,

Daniel R. Dietrich

daniel.dietrich@uni-konstanz.de

1 Human and Environmental Toxicology, Department of Biology, University of Konstanz, Konstanz, Germany

2 Present Address: Brain Cancer Metabolism Group, German Cancer Research Center (DKFZ), Heidelberg, Germany

3 Boehringer Ingelheim Pharma GmbH \& Co. KG, Non-Clinical Drug Safety, Biberach, Germany xenobiotics, and water from the primary urine as well as excretion of metabolic waste products and hydrophilic and amphiphilic xenobiotics. Compounds exhibiting doselimiting nephrotoxicity include drugs from highly diverse classes and chemical structures, e.g., antibiotics (gentamicin), chemotherapeutics (cisplatin), immunosuppressants (cyclosporine A and tacrolimus) or bisphosphonates (zoledronate). Common to these compounds is that they elicit nephrotoxicity primarily by injuring renal proximal tubule epithelial cells (RPTECs) (Miller et al. 2010; Naesens et al. 2009; Perazella and Markowitz 2008; Quiros et al. 2011). RPTECs are responsible for the lion's share of renal secretion and solute reabsorption (Lepist and Ray 2016) and thus present with high transport capabilities and metabolic rates (Hall and Unwin 2007). As a result of the latter, RPTECs experience a high exposure to drugs thereby rendering these cells especially vulnerable toward drug-mediated adverse effects. Despite their known risk 
of causing kidney injury, many drugs-including those introduced above-are routinely used in clinics, mostly because of a lack of nontoxic or similarly efficient but less-toxic alternatives. Thus, development of new drugs with decreased risk for nephrotoxicity would provide for a huge patient benefit and would widen therapeutic windows. Moreover, elderly patients, usually with a lowered renal function (Pazhayattil and Shirali 2014), not only represent a specially high-risk group, but are often exposed to a multitude of drugs simultaneously, thereby facing an increased risk of renal injury due to drug overdosing resulting from the preexisting reduced renal function or from polypharmacy and thus potential combined drug renal toxicity (Loboz and Shenfield 2005). In contrast to the latter needs, prediction of a compound's nephrotoxic potential in humans to support early de-risking of drug candidates remains an unmet challenge, mainly due to the complex kidney anatomy as well as pronounced inter- and intraspecies differences and lack of relevant, robust, sensitive, and validated human in vitro models (Tiong et al. 2014). With regard to human-derived cells, the latter is mainly due the unavailability of functionally differentiated continuous cell lines (Tiong et al. 2014) and the rapid dedifferentiation of primary RPTECs in culture (Pfaller and Gstraunthaler 1998). Thus human cell lines that maintained key functionalities including xenobiotic uptake and secretion are of key interest especially for pharmaceutical research and development. The RPTEC/TERT1 cell line was recently established by immortalizing primary human RPTECs via telomerase (TERT1) overexpression (Wieser et al. 2008). Subsequent gene expression analysis revealed remarkable concordance of RPTEC/TERT1 cells with primary human RPTECs. Furthermore, RPTEC/TERT1 cells retain important functional characteristics such as dome formation (Wieser et al. 2008), water (Wilmes et al. 2014) and cation transport (Aschauer et al. 2015a). Consequently, this cell line has been used for in-depth repeated dose nephrotoxicity studies (Aschauer et al. 2015b) as well as to study the underlying mechanisms of cyclosporine A (Wilmes et al. 2013) and cisplatin (Wilmes et al. 2015) toxicity. However, the latter was carried out primarily with a focus on transcriptomic, metabolomic, and proteomic approaches and not with a focus on functional characteristics. While functional readouts are commonly applied for the in vitro detection of neuro- (Hausherr et al. 2014) or cardiotoxicity (Sirenko et al. 2017), such approaches have so far been rarely applied for the detection of nephrotoxicity and, when applied, were basically limited to measurements of transepithelial electrical resistance (Duff et al. 2002). Thus, in the present study, we investigated whether the combination of functional measurements, e.g., water reabsorption and cation secretion with classical cytotoxicity endpoints, while using a limited set of nephrotoxic and non-nephrotoxic reference substances, could provide for improved sensitivity in the detection of drug-induced nephrotoxicity.

\section{Results}

\section{RPTEC/TERT1 cell viability upon single or multiple exposures with known nephrotoxicants}

Cultivation of RPTEC/TERT1 cells on standard tissue culture plates for 16 days resulted in a monolayer of non-dividing, differentiated cells reminiscent of fully functional primary human proximal tubule cells (Aschauer et al. 2015a). We exposed these differentiated RPTEC/TERT1 cells to a set of test compounds comprised of nephrotoxicants with reported primary proximal tubule toxicity (cisplatin, zoledronate, gentamicin, tacrolimus, and cyclosporine A) and compounds being specifically handled by the kidney yet lacking nephrotoxicity (dexamethasone and probenecid). Cells were exposed either for $24 \mathrm{~h}$ or 14 day with treatment renewal every $48 \mathrm{~h}$ followed by determination of cell viability via MTT reduction assay. Remarkably, cisplatin, gentamicin, and zoledronate were more cytotoxic when applied repeatedly for 14 days than for $24 \mathrm{~h}$ (Fig. 1), whereas the immunosuppressants tacrolimus and cyclosporine A showed limited or no cytotoxicity irrespective of single or repeated exposure. Indeed, repeated treatment with cisplatin (Fig. 1a) and gentamicin (Fig. 1b) resulted in reducing the lowest observed effect concentration (LOEC) by almost 200-fold (from 300 to $1.6 \mu \mathrm{M}$ ) and 60-fold (from $22.5 \mathrm{mM}$ to $350 \mu \mathrm{M})$, respectively, when compared to the LOEC of the $24 \mathrm{~h}$ treatment. Zoledronate (Fig. 1c) did not impair cell viability in the $24 \mathrm{~h}$ exposure, even when tested up to the limit of compound solubility, but significantly reduced cell viability, with a LOEC of $12.5 \mu \mathrm{M}$, when tested for 14 day. Tacrolimus treatment (Fig. 1d) resulted in a very steep concentration-response curve irrespective of the exposure duration and single or multiple treatment, i.e., showing no effect at $63 \mu \mathrm{M}$ but complete loss of viability at $100 \mu \mathrm{M}$. In contrast, despite being tested up to the limit of solubility, the known nephrotoxicant cyclosporine A did not affect cell viability at all (Fig. 1e). Similarly, the non-nephrotoxic probenecid (Fig. 1f) and dexamethasone (Fig. 1g) had no effect on cell viability when tested up to $1 \mathrm{mM}$ or $500 \mu \mathrm{M}$ in the $24 \mathrm{~h}$ or 14 day repeated exposures. On the contrary, repeated dexamethasone exposure appeared to result in increased MTT conversion rates.

\section{Cellular impedance as a real-time measure of cytotoxicity in RPTEC/TERT1 cells}

The $x$ CELLigence system provides a real-time, label-free and non-invasive readout, expressed as cell index, that 

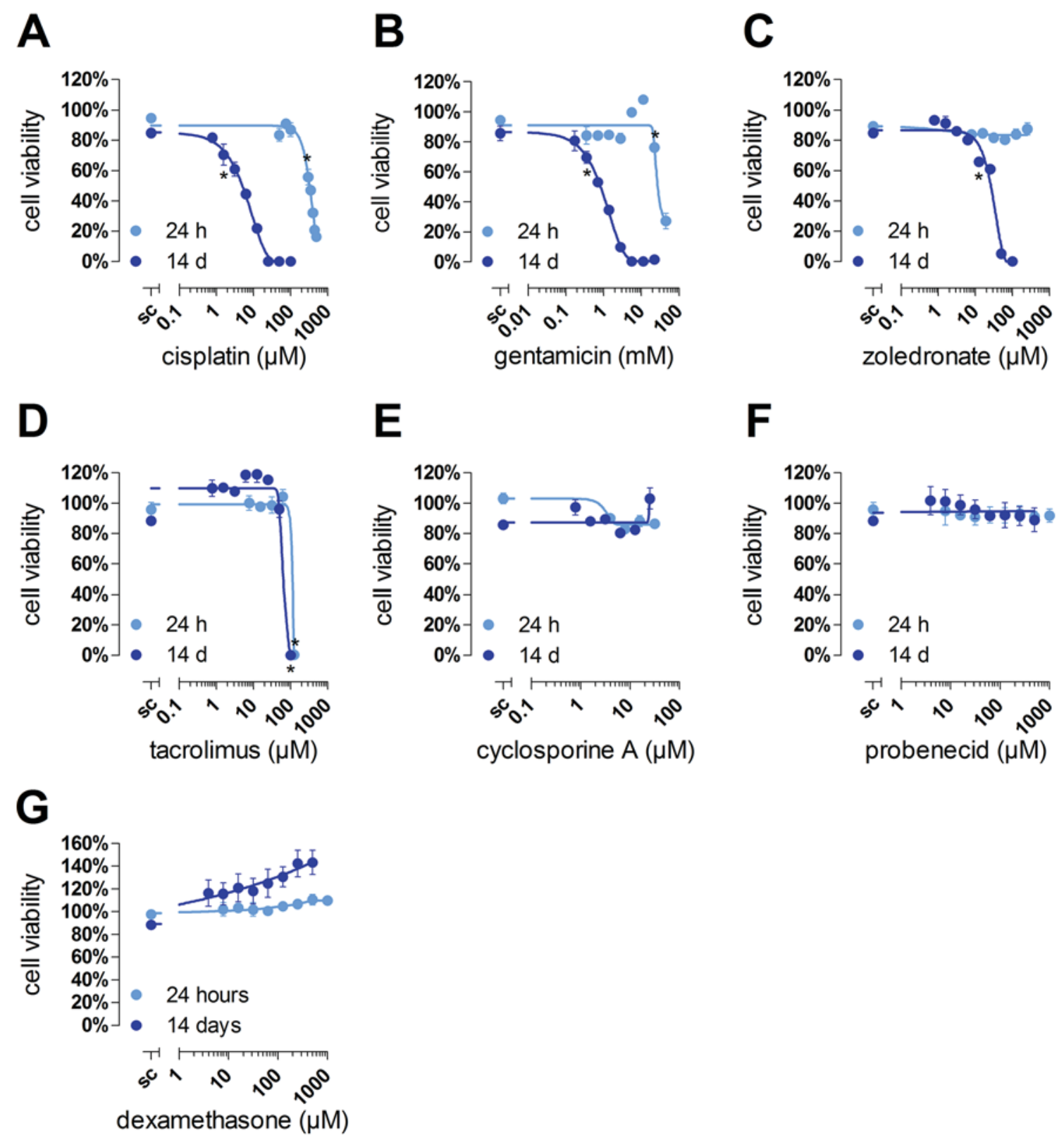

Fig. 1 Viability of RPTEC/TERT1 cells exposed to test compounds. Differentiated RPTEC/TERT1 cells (16 day) were exposed to (a) cisplatin, b gentamicin, c zoledronate, $\mathbf{d}$ tacrolimus, e cyclosporine A, $\mathbf{f}$ probenecid or $\mathbf{g}$ dexamethasone for $24 \mathrm{~h}$ or $14 \mathrm{~d}$ with treatment renewal every 2 days in presence of $1 \%$ DMSO $(24 \mathrm{~h} ; \mathrm{sc})$ or $0.5 \%$

primarily depends on cellular adherence to the plate and on the intensity of cell-cell connections, thus reflecting a direct relationship to cell density and cell layer integrity (Asphahani and Zhang 2007). We thus hypothesized that cellular impedance measurements in repeated exposure experiments, using the xCELLigence system, would allow for sensitive detection of subtle changes in cell-cell interactions and cellular adhesion that would not necessarily lead to overt cell death in RPTEC/TERT1 cells. A strengthening of cell-cell
DMSO (14 day; sc). Cell viability was determined via MTT reduction. Data show mean $\pm \operatorname{SEM}(n=3)$ and was normalized to nontreated cells. ${ }^{*} P<0.05$, ANOVA with Dunnett's post-test. The lowest concentration with significant reduction in viability is marked with an asterisk

interactions, i.e., tight junctions, would be represented by an increase in cell index, while a weakening of cell-cell interactions or even loss of cells would result in a decreased cell index. The absolute value of the cell index varies between cell lines and thus has no absolute but rather a relative value. Following 8-10 days of culture, RPTEC/TERT1 cells seeded at different densities, i.e., initially covering $10-50 \%$ of the surface area, developed a cell index that remained stable for the subsequent 20 days of culture (Fig. 2a). The periodically 
Fig. 2 Impedance measurement of RPTEC/TERT1 cells using xCELLigence. a Cell index of RPTEC/TERT seeded at different densities monitored over 30 days. Data represent mean $\pm \operatorname{SEM}(n=3)$. b-h Change in cell index of RPTEC/TERT1 cells exposed to different concentrations of b cisplatin, $\mathbf{c}$ gentamicin, $\mathbf{d}$ zoledronate, $\mathbf{e}$ tacrolimus, $\mathbf{f}$ cyclosporine A, $\mathbf{g}$ probenecid or $\mathbf{h}$ dexamethasone in presence of $0.5 \%$ DMSO. Based on results depicted in a, RPTEC/TERT 1 cells were seeded at $30 \%$ and cultured for 16 day prior to exposure (day 0). Data show mean values of a representative experiment performed in quadruplicates and is normalized to time-matched values obtained for non-treated cells. Vertical dotted lines indicate medium or treatment renewal. i Average change of cell index of exposed cells from non-treated cells over the complete experimental duration (14 day). Data represent mean $\pm \operatorname{SEM}(n=3)$. $* P<0.05$; *** $P<0.001 ;$ n.s. not significant compared to s.c. (0.5\% DMSO), ANOVA + Dunnett's post-test

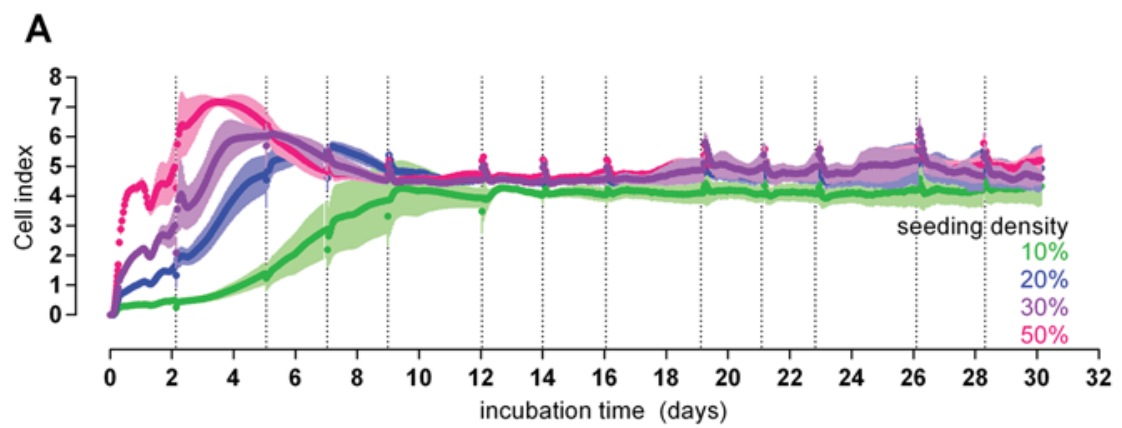

B

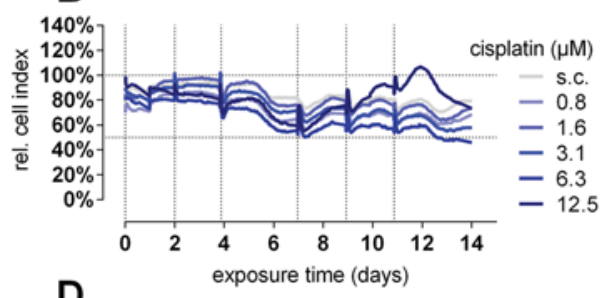

$$
\text { D }
$$

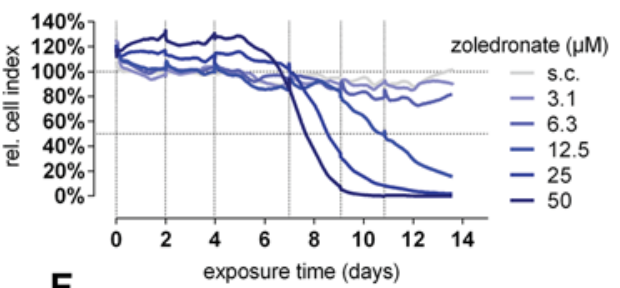

\section{F}

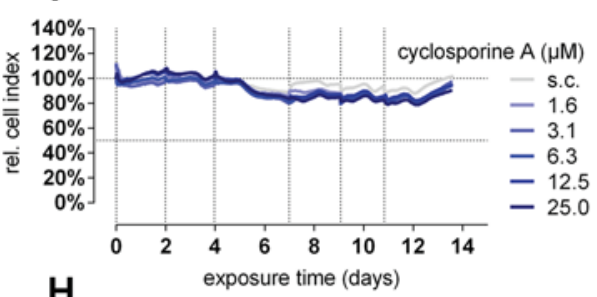

$\mathrm{H}$

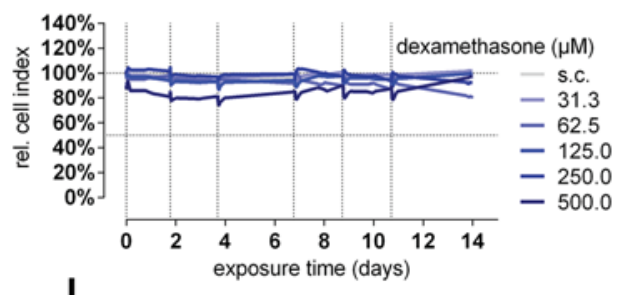

I

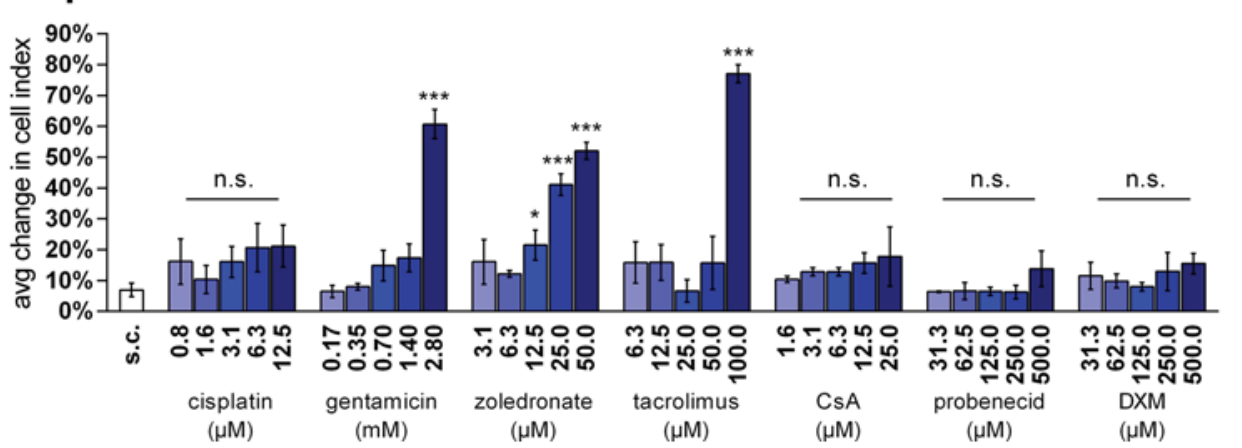

C

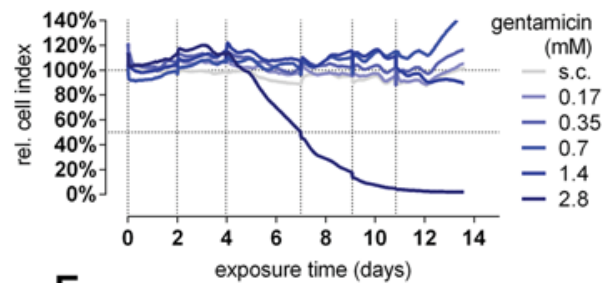

E

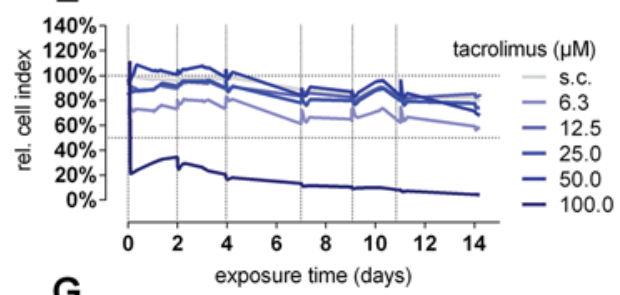

G

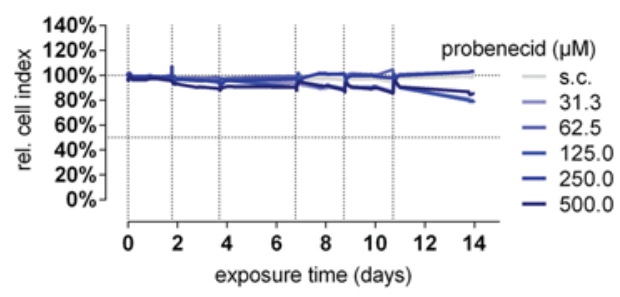
cin
M.c.
0.17
0.35
0.7
1.4
2.8



M)
$5 . c$.
6.3
12.5
25.0
50.0
100.0 0.17
0.35
0.7 . 
occurring peaks observed (Fig. 2a) originated from medium renewal (indicated by the vertical dotted lines). Next, we exposed differentiated RPTEC/TERT1 cells (cultivated for 16 days) repeatedly for 14 days to the test compounds at concentrations that were identified as cytotoxic (MTT reduction) in the multiple exposure experiment (Fig. 1) and continuously quantified cell indices. For compounds that showed no effect on MTT reduction, the highest five concentrations (Fig. 1) were selected for the xCELLigence experiment. The nephrotoxins cisplatin (Fig. 2b) and gentamicin (Fig. 2c) showed surprisingly little effect on the cell index. While cisplatin did not impact the readout up to $12.5 \mu \mathrm{M}$, gentamicin caused a progressive reduction of the cell index at the highest concentration $(2.8 \mathrm{mM})$ employed and only after the third treatment renewal. In case of zoledronate (Fig. 2d), good concordance between MTT and impedance measurements was observed since both readouts identified $12.5 \mu \mathrm{M}$ as the lowest effect concentration for the 14-day exposure period (Figs. 1c, 2d, i). Additionally, the xCELLigence experiment nicely revealed that zoledronate toxicity strongly depends on exposure time and/or dosing frequency. Indeed, a reduction of the cell index was initially observed at day 6 (after three treatments) for $50 \mu \mathrm{M}$ and approximately 1 day later for $25 \mu \mathrm{M}$. At $12.5 \mu \mathrm{M}$, progressive decrease in cell index was not observed until day 9 (five treatments). Interestingly, the treatment with $100 \mu \mathrm{M}$ tacrolimus (Fig. 2e) caused an immediate loss of cellular impedance while up to $50 \mu \mathrm{M}$ did not show any effect even not after multiple exposures. The latter corresponded well with the MTT data (Fig. 1d) that showed the complete loss of viability at $100 \mu \mathrm{M}$ after $24 \mathrm{~h}$ but unimpaired viability at $50 \mu \mathrm{M}$ after 14 days. The other nephrotoxic calcineurin inhibitor, cyclosporine A, did not affect cellular impedance (Fig. 2f) similar to the non-nephrotoxic compounds dexamethasone (Fig. $2 \mathrm{~g}$ ) and probenecid (Fig. 2h) thereby mirroring the data obtained from the MTT assays.

Statistical mean values were employed to better enable identification of whether or not a treatment caused an alteration in the cell index. Thus, an internal normalization of the individual experiments was unavoidable. For the latter we decided to calculate the change (increase and decrease) in cell index caused by a defined treatment by dividing the cell index of the treated cells at a given timepoint by the value obtained for non-treated cells on the same plate at the same timepoint. The average change in cell index was then calculated by building the mean across the changes at all timepoints of each experiment (see formula in Fig. $\mathrm{S} 1$ ). This normalization showed that the average change in cell index caused by the solvent control (s.c.; 0.5\% DMSO) compared to non-treated cells was below $10 \%$ (Fig. 2i). Statistically significant changes in cell index were detected for gentamicin $(2.8 \mathrm{mM})$, zoledronate (starting at $12.5 \mu \mathrm{M})$, and tacrolimus (100 $\mu \mathrm{M})$ (Fig. 2i).

\section{Transepithelial electrical resistance as a functional toxicity readout using RPTEC/TERT1 cells}

The proximal tubule is a "leaky" epithelium, characterized by intense cell-cell contacts including tight junctions which, however, still allow for paracellular transport required for the functionality of the proximal tubule epithelium, i.e., reabsorption and secretion of solutes. Thus, cultivation on trans-well membrane filter inserts is considered the gold standard for renal proximal tubule cells since it allows the basolateral-apical polarization of the cells commensurate with their anatomical situation and functional organization. The integrity of the renal proximal epithelium-like monolayer on membrane filters can be quantified by its insulating property as transepithelial electrical resistance (TEER). When seeded on trans-well membrane filters at $100 \%$ confluence, RPTEC/TERT1 cells build up electrical resistance, stabilizing between $120-140 \Omega \times \mathrm{cm}^{2}$ at approximately 14 days and thereafter (Fig. 3a). To determine the effect of potential nephrotoxic compounds on the "leakiness" of the renal proximal tubule cell epithelium using TEER, we repeatedly exposed confluent, 23 days-cultured RPTEC/TERT 1 to the test compounds at concentrations that were determined to have no effect (or little effect in case of zoledronate) by the xCELLigence assay (Fig. 2i) and quantified TEER every 2-3 days. To ensure for a stable baseline in TEER prior to the exposure period, measurements were initiated 9 days prior to exposure initiation (day -9). An increase in TEER would represent an increased tightening of the cell-cell contacts and thus reduced leakiness of the monolayer, while a decreased TEER would suggest increased leakiness thus increased weakening of the tight junctions or even cell death.

Exposure to cisplatin (12.5 $\mu \mathrm{M})$ (Fig. 3b) caused a significant but transient increase in TEER between day 2 and 7 of exposure only to return to baseline for days 9-14. As expected, increasing the concentration of cisplatin to 25 and $50 \mu \mathrm{M}$ resulted in a decrease in TEER at later timepoints suggesting cytotoxicity (Fig. 3b). In contrast, gentamicin $(700 \mu \mathrm{M})($ Fig. 3c) caused an increase in TEER on days 9 and 12 of exposure, while zoledronate $(12.5 \mu \mathrm{M})$ (Fig. $3 \mathrm{~d})$ did not affect TEER at any timepoint. Tacrolimus $(50 \mu \mathrm{M})$, on the other hand, caused an immediate elevation of TEER (Fig. 3e), already detectable after $9 \mathrm{~h}$ of exposure and maintained until day 9, after which normalization to baseline occurred. $10 \mu \mathrm{M}$ tacrolimus (Fig. 3e), however, had no effect on TEER. Cyclosporine A at $5 \mu \mathrm{M}$ (Fig. 3f) immediately (after $9 \mathrm{~h}$ ) elevated TEER over the entire exposure period of 14 days. At $25 \mu \mathrm{M}$, TEER peaked at $425 \Omega \times \mathrm{cm}^{2}$ at day 2 before it returned to normal around day 9 . The two nonnephrotoxic compounds probenecid (Fig. 3g) and dexamethasone (Fig. 3h) both caused transient increases of TEER at $500 \mu \mathrm{M}$ but not at $50 \mu \mathrm{M}$. None of the test compounds induced a reduction of TEER at concentrations deemed 
Fig. 3 Transepithelial electrical resistance (TEER) measurements of RPTEC/TERT1 cells. a RPTEC/TERT1 cells were seeded on membrane filter inserts at $100 \%$ confluence and TEER was measured over a period of 38 days. Data represent mean \pm SEM of ( $n=20-130$ filter inserts per timepoint). b-h Changes in TEER due to exposure to b cisplatin, $\mathbf{c}$ gentamicin, $\mathbf{d}$ zoledronate, $\mathbf{e}$ tacrolimus $\mathbf{f}$ cyclosporine A, $\mathbf{g}$ probenecid or $\mathbf{h}$ dexamethasone. Exposure was initiated at day 23 after seeding (indicated as day 0 ) and TEER quantification was started 9 days prior to exposure (day -9). Exposure was performed for 14 days with medium renewal every 2-3 days. Data represent mean $\pm \mathrm{SD}(n=3) . * P<0.05$ compared to time-matched controls (0.5\% DMSO), twoway ANOVA + Bonferroni's post-test
A
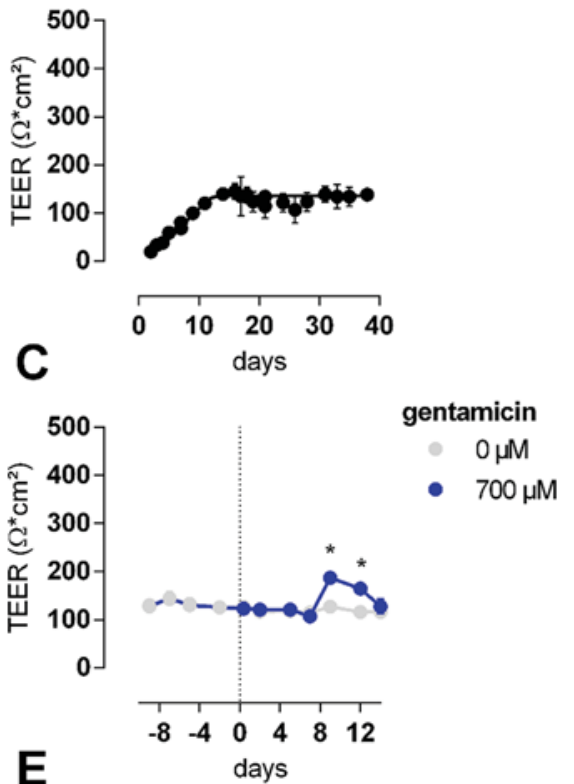

E

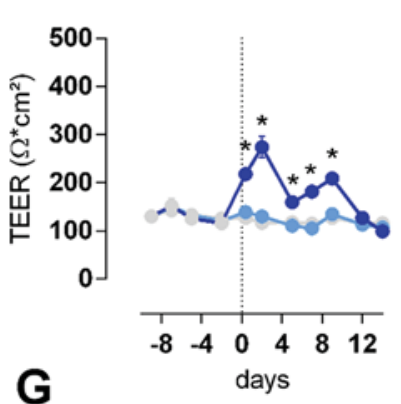

\section{tacrolimus}

- $0 \mu \mathrm{M}$

- $10 \mu \mathrm{M}$

- $50 \mu \mathrm{M}$

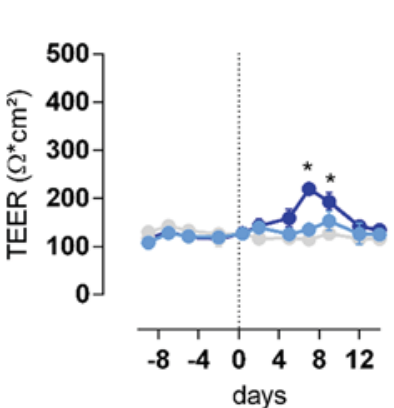

B
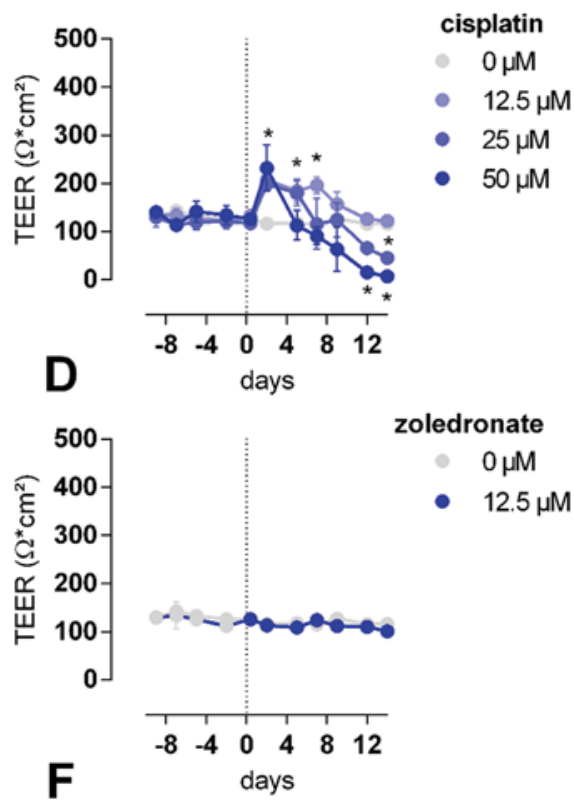

ledronate

- $12.5 \mu \mathrm{M}$
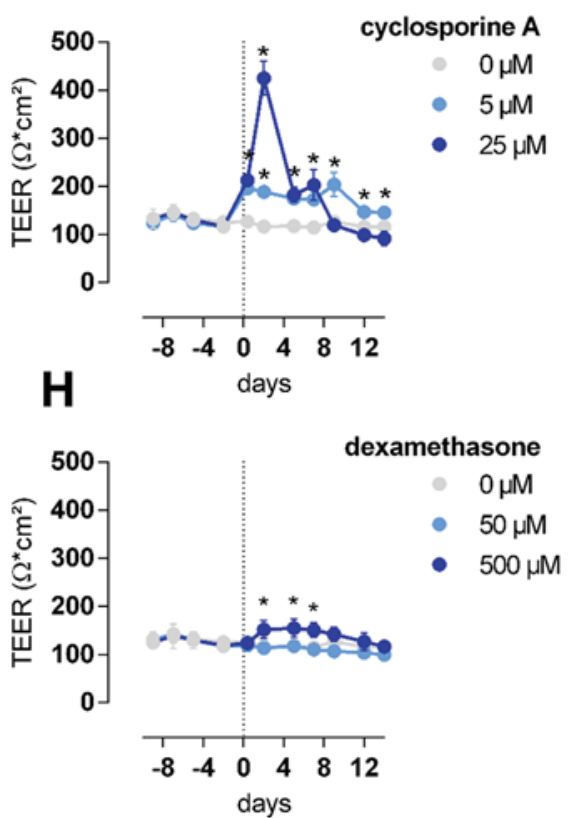

non-cytotoxic. The latter suggests that RPTEC/TERT1 cells do not exhibit higher sensitivity on trans-well membrane filter inserts when compared to 2D plastics exposures, as used in the xCELLigence assay.

\section{Vectorial transport of RPTEC/TERT1 cells}

Beyond the pronounced cell-cell contacts of an established renal proximal tubule epithelial cell layer, active vectorial transport processes represent the key functionality of the proximal tubule epithelium (Morrissey et al. 2013). Indeed, when RPTEC/TERT1 cells were cultured on trans-well membrane inserts, active vectorial water transport was readily apparent, intensified with increasing cultivation time and was quantifiable simply by measuring water removal from the apical compartment (insert) or water addition to the basolateral compartment (well) using an analytical scale (Fig. 4a). Water reabsorption is a passive process that primarily depends on the establishment of a confluent and polarized cell layer, tight junctions, expression of aquaporins and an osmotic gradient foremost established by the $\mathrm{Na}^{+} / \mathrm{K}^{+}$-ATPase expressed at the basolateral membrane, illustrated by the complete 
A

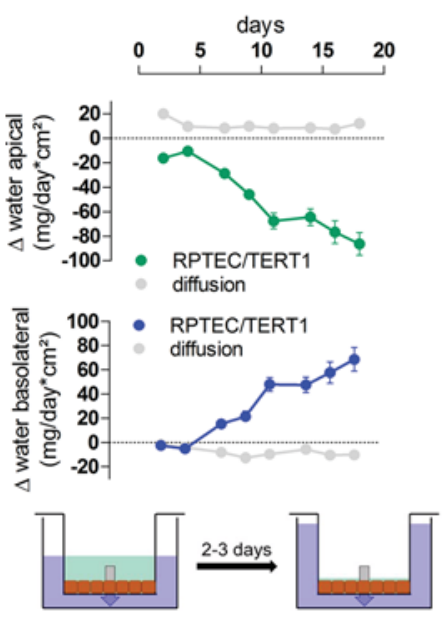

D
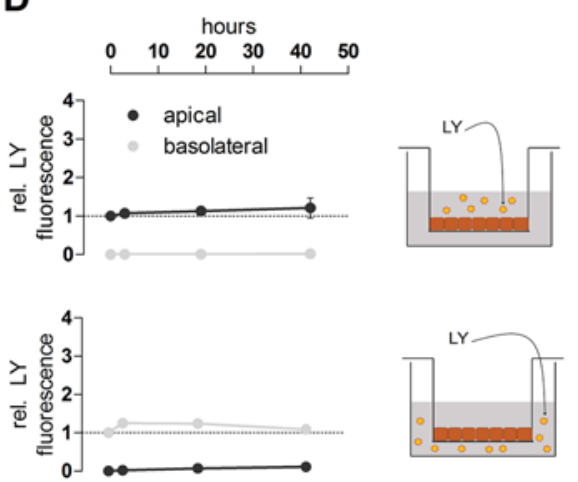

B

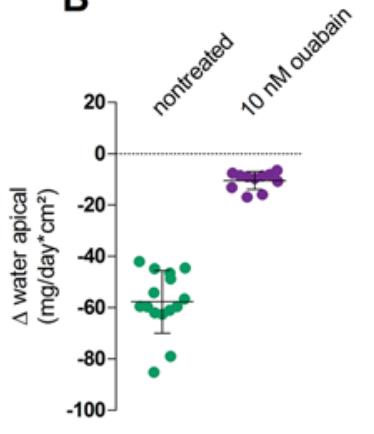

C
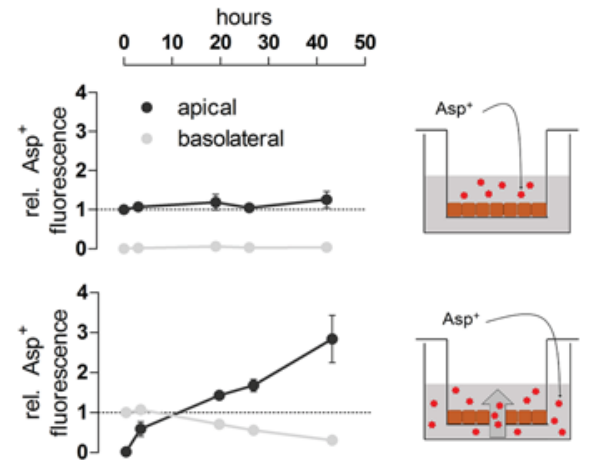

E

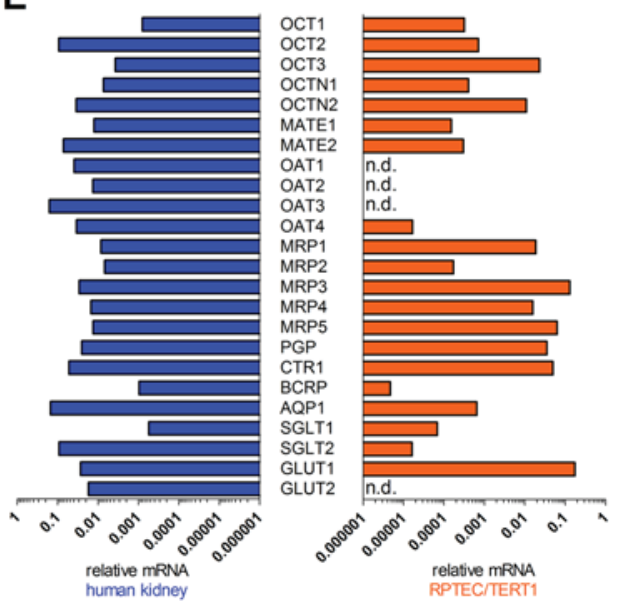

Fig. 4 Vectorial transport processes of RPTEC/TERT1 cell on membrane filters. a Water transport of RPTEC/TERT1 cells over time quantified as removal from apical side or addition to basolateral side in $\mathrm{mg}$ per day and membrane surface area in $\mathrm{cm}^{2}$. Data represent mean \pm SEM $(n=4)$. Diffusion shows water exchange in wells without cells. b Water transport in the presence and absence of the $\mathrm{Na}^{+} /$ $\mathrm{K}^{+}$-ATPase inhibitor ouabain. c Vectorial transport of 4-Di-1-ASP $\left(\mathrm{Asp}^{+}\right.$) by RPTEC/TERT1 cells in (upper panel) apical-to-basolateral direction and (lower panel) basolateral-to-apical direction. Data

abrogation of water transport by inhibition of the $\mathrm{Na}^{+} /$ $\mathrm{K}^{+}$-ATPase with ouabain (Fig. 4b) (Wilmes et al. 2014).

Functional water reabsorption suggests in vivo-like polarization of RPTEC/TERT1 cells on trans-well membrane inserts and hence it was suggested that the cells might also be capable of secreting xenobiotics. To determine the capacity of RPTEC/TERT1 to actively secrete xenobiotics, we used the cationic fluorescent probe 4-Di-1-ASP $\left(\mathrm{Asp}^{+}\right)$, a substrate for the OCT/MATE transport axis (Aschauer et al. 2015a; Sauzay et al. 2016) and the fluorescent anion Lucifer yellow (LY), secreted via the OAT/MRP axis (Masereeuw et al. 1999). As expected for a substance that undergoes secretion, $\mathrm{Asp}^{+}$remained in the apical compartment with no represent mean \pm SD of 3 membrane filters. d Vectorial transport of Lucifer Yellow (LY) by RPTEC/TERT1 cells in (upper panel) apical to basolateral direction and (lower panel) basolateral to apical direction. Data represent mean \pm SD of 3 membrane filters. e Gene expression of various transporters in RPTEC/TERT1 cells cultured on membrane inserts and human kidney. Data show mean expression of four independent RPTEC/TERT1 samples and one human kidney sample analyzed in duplicates. n.d. not detected

fluorescence detectable in the basolateral medium (Fig. 4c, upper panel). However, when added to the basolateral compartment, $\mathrm{Asp}^{+}$was efficiently and actively transported into the apical compartment (Fig. 4c, lower panel). LY on the other hand was not transported in either direction (Fig. 4d), suggesting absence of functional anion transport. Subsequently, gene expression analysis of transporters in the confluent RPTEC/TERT1 cell monolayer, in contrast to human cortical kidney (Fig. 4e), demonstrated that the confluent RPTEC/TERT1 cell epithelium lacked expression of OATs $1-3$. The absence of OAT1 and OAT3, as the primary anion importers (Morrissey et al. 2013), would explain the lack of LY transport. However, apart from the latter deficit, RPTEC/ 
TERT1 cells appear to express most of the important renal transporters including OCT1-3, MATE1-2, MRP1-5, P-gp, AQP1, etc. (Fig. 4e).

\section{Vectorial transport as a functional readout for the detection of nephrotoxicity}

Since cellular dedifferentiation and concomitant impairment in functionality are common features of early toxicity (Puri et al. 2015), it was hypothesized that an impairment of water transport or $\mathrm{Asp}^{+}$secretion would be a sensitive indicator of toxicity. To test this, confluent RPTEC/TERT1 cells cultured on trans-well membrane inserts were exposed to the test compounds for 9 consecutive days followed by a 14-day recovery period. Water reabsorption was quantified throughout the whole study period and $\mathrm{Asp}^{+}$secretion was measured at three distinct time points throughout exposure and recovery (Fig. 5a). Exposure to $12.5 \mu \mathrm{M}$ cisplatin (Fig. 5b) and $700 \mu \mathrm{M}$ gentamicin (Fig. 5c) resulted in gradually reduced water reabsorption during the exposure phase, whereby no overt recovery was observed up until day 23 (14 day post exposure recovery period). Conversely, $12.5 \mu \mathrm{M}$ zoledronate (Fig. $5 \mathrm{c}$ ) had no effect on water reabsorption at any time point investigated. The most dramatic effects were observed with $50 \mu \mathrm{M}$ tacrolimus (Fig. 5e) and $25 \mu \mathrm{M}$ cyclosporine A (Fig. 5f). Both compounds caused an immediate reduction of water transport that peaked at day 9 of exposure when only $30-40 \%$ of the water transport capacity remained. Interestingly, upon removal of the compounds water transport gradually recovered and returned back to normal at 10 days of recovery. Exposure to $500 \mu \mathrm{M}$ probenecid (Fig. $5 \mathrm{~g}$ ) decreased water reabsorption gradually during the exposure phase; however, the cells did not recover until day 23. Conversely, exposure to $50 \mu \mathrm{M}$ probenecid led to a very slight reduction of water transport, which appeared fully reversible. The other typically non-nephrotoxic compound, dexamethasone $(500 \mu \mathrm{M})$, strongly decreased water transport in a linear fashion until day 9 , when only $40 \%$ of the water transport capacity remained. However, the water transport capacity gradually recovered during the recovery period reaching $80-90 \%$ of the original capacity at day 14 of recovery. At a lower concentration of $50 \mu \mathrm{M}$, the effect of dexamethasone was less pronounced, decreasing water transport to $70 \%$ after 9 days of exposure with cells recovering completely after 14 days. Secretion of $\mathrm{Asp}^{+}$was determined from day 7 to 9 of exposure and, in case of the known nephrotoxicants, during recovery from day 12 to 14 and day 21 to 23 (Fig. 5a). The comparison of $\mathrm{Asp}^{+}$transport of dye diffusion through trans-well membrane filters without cells (Fig. 6a, diffusion) with transport in DMSO-treated cells (Fig. 6a, 0.5\% DMSO), demonstrated the active transport of the dye when cells are present. RPTEC/TERT1 cells treated for 7 days with gentamicin, cisplatin, probenecid, and zoledronate showed a slightly elevated $\mathrm{Asp}^{+}$transport (Fig. 6a) although this effect was only significant for gentamicin (Fig. 6b). Interestingly, exposure to $500 \mu \mathrm{M}$ dexamethasone resulted in a transport kinetic that was strikingly similar to the diffusion control (Fig. 6a), suggesting that dexamethasone rendered the monolayer permeable to $\mathrm{Asp}^{+}$and consequently impaired active transport, as was also indicated by quantification of water transport (Fig. 5h). The strongest effects on $\mathrm{Asp}^{+}$secretion were again observed for cyclosporine A and tacrolimus, both almost completely abolishing Asp $^{+}$transport after 7 days of exposure (Fig. 6a).

To accurately quantify $\mathrm{Asp}^{+}$secretion over the $48 \mathrm{~h}$ period, the simultaneously occurring water transport had to be taken into account. Asp ${ }^{+}$fluorescence determined at the last time-point $(47 \mathrm{~h})$ was therefore, corrected for the medium volume present in the apical compartment at that specific timepoint (Fig. 6b, c). Even after this correction, cyclosporine A and tacrolimus almost completely eliminated relative $\mathrm{Asp}^{+}$transport on day 7 of treatment (Fig. 6c). Gentamicin, on the other hand, significantly increased Asp ${ }^{+}$ secretion, while none of the other compounds changed the total amount of $\mathrm{Asp}^{+}$transported. Both increased and decreased $\mathrm{Asp}^{+}$secretion returned back to normal within the recovery phase (from day 9 to 23 , see Fig. 5a). In case of cyclosporine A, reduced transport was still visible after 3 days of recovery (day 12) but returned back to normal after 12 days recovery (day 21 ), while the effects of tacrolimus and gentamicin were already abolished at day 12 .

\section{Discussion}

About one third of drug-development failures occurring during clinical studies are due to safety reasons (Waring et al. 2015) and the kidney is one major organ affected by adverse drug reactions (Lin and Will 2012). As nephrotoxicity affects the functionality and viability of RPTECs (Paueksakon and Fogo 2017), depicting the functionality of these cells in vitro is of key importance for the development of alternative test methods to detect potential nephrotoxins. Unfortunately, there is no human RPTEC cell line available with fully preserved capacity for xenobiotic transport (Tiong et al. 2014) thus limiting their suitability for detection of nephrotoxicity. Indeed, one of the most frequently used human tubular epithelial cell lines, HK-2, was reported to lack expression of the key transporters OAT1, OAT3, OCT2, and BCRP (Jenkinson et al. 2012), whereas, more recently established cell lines, including the RPTEC/TERT1 cell line, were reported to have retained important functional parameters (Aschauer et al. 2015a; Wilmes et al. 2014).

Simple cell viability assays are often disparaged due to their unspecific nature and indeed MTT reduction was not a sensitive readout when analyzed after an acute $24 \mathrm{~h}$ exposure 
Fig. 5 Vectorial water transport as a functional parameter to detect nephrotoxicity. a Schematic of the experimental setup designed to investigate the effects of the test compounds on water and $\mathrm{Asp}^{+}$transport. Cells were seeded 23 days prior to exposure initiation. Medium with (exposure phase) or without (recovery phase) compounds was renewed at the days indicated. Water and $\mathrm{Asp}^{+}$ transport were quantified in the highlighted intervals. $\mathbf{b}-\mathbf{h}$ Compound-induced change in water transport as quantified in the apical compartment. Relative water transport of cells exposed to b $12.5 \mu \mathrm{M}$ cisplatin, c $700 \mu \mathrm{M}$ gentamicin, $\mathbf{d}$ $12.5 \mu \mathrm{M}$ zoledronate, e $50 \mu \mathrm{M}$ tacrolimus, $\mathbf{f} 25 \mu \mathrm{M}$ cyclosporine $\mathrm{A}, \mathrm{g} 50 \mu \mathrm{M}$ and $500 \mu \mathrm{M}$ probenecid and $\mathbf{h} 50 \mu \mathrm{M}$ and $500 \mu \mathrm{M}$ dexamethasone. Data represent mean $\pm \operatorname{SEM}(n=4)$ normalized to time-matched controls (0.5\% DMSO)

A

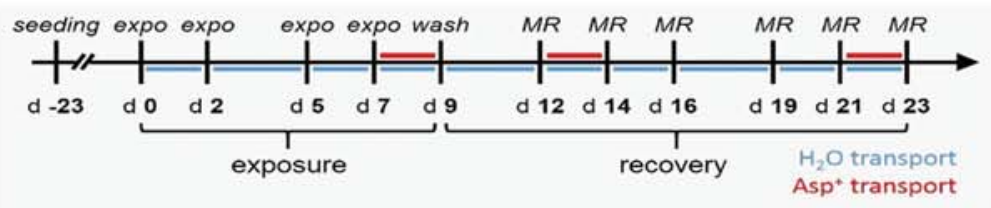

B

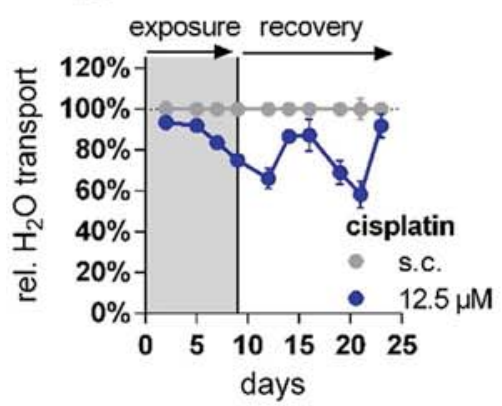

D

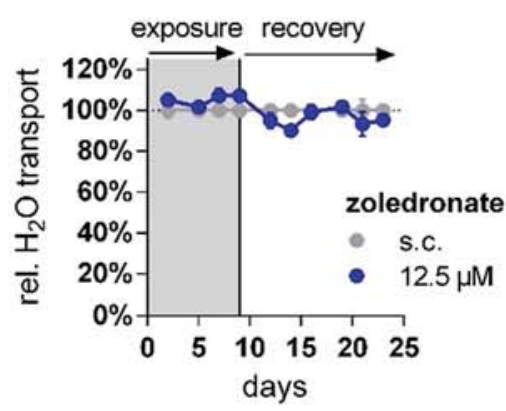

F

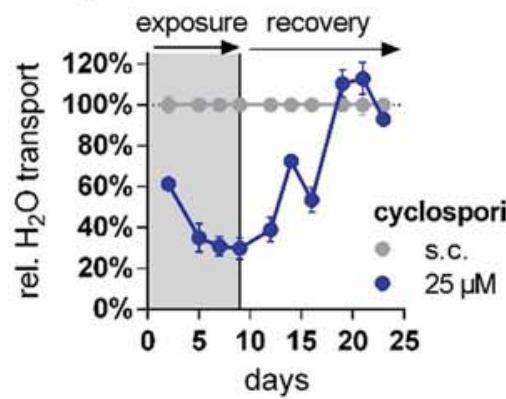

H

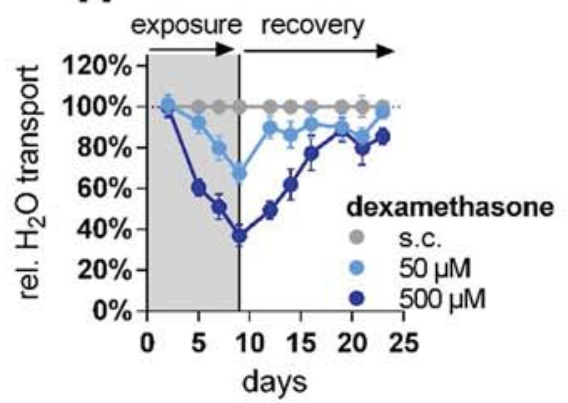

C

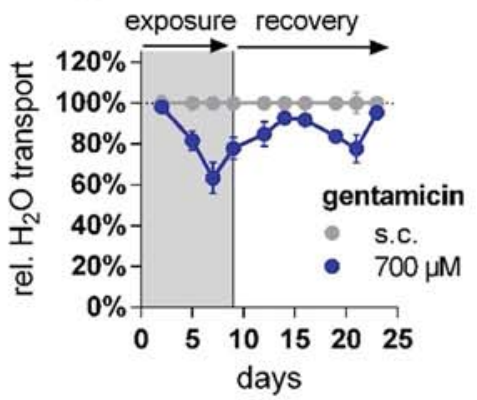

E

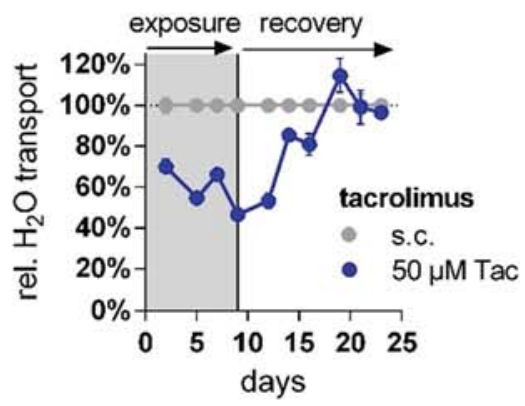

G

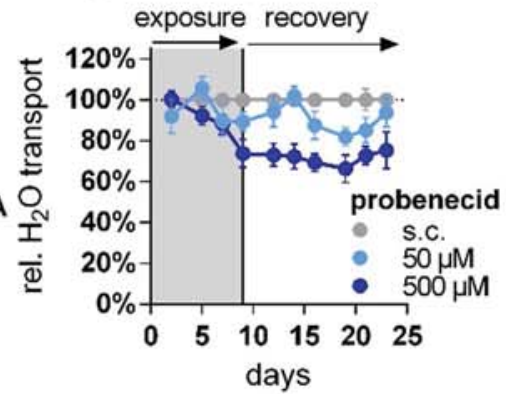



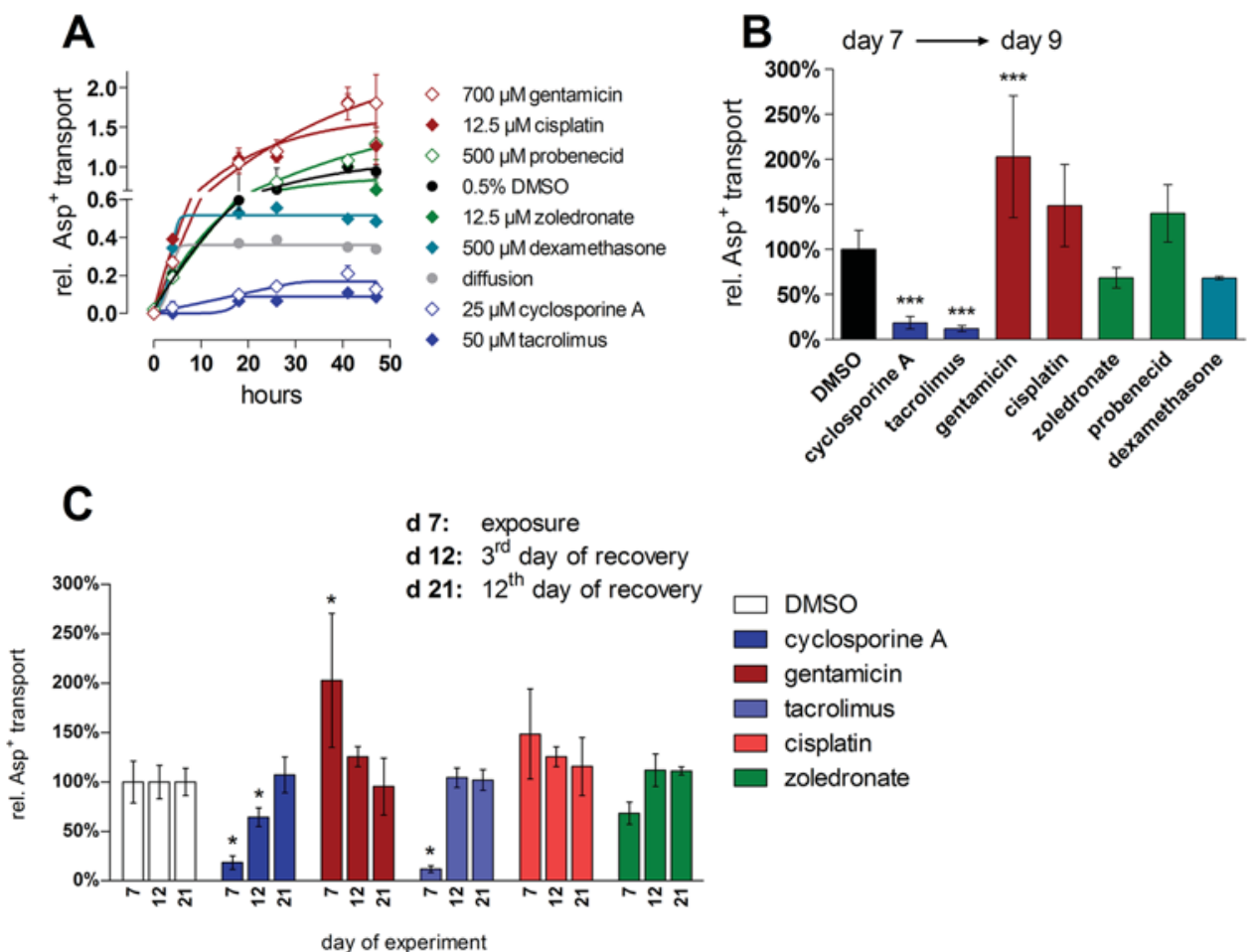

Fig. $6 \mathrm{Asp}^{+}$secretion by RPTEC/TERT1 cells exposed to the test compounds. a Time dependency of $\mathrm{Asp}^{+}$fluorescence in the apical compartment. Experiment was initiated after 7 days of exposure in presence of the compounds indicated. Fluorescence was normalized towards values obtained for $0 \mathrm{~h}$ in the basolateral compartment where the dye was added. b Absolute Asp ${ }^{+}$fluorescence in the apical compartment after $47 \mathrm{~h}$ (from day 7 to day 9) normalized to water content. c Absolute $\mathrm{Asp}^{+}$fluorescence in the apical compartment after $47 \mathrm{~h}$ normalized to water content at all different timepoints. Data represent mean \pm SEM $(n=4)$ normalized to time-matched controls (0.5\% DMSO). $* P<0.05 ; * * * P<0.001$, compared to time-matched controls (0.5\% DMSO), two-way ANOVA + Sidak's post-test to the test compounds in our hands. However, when used at the end of a 14-days repeated exposure experiment with RPTEC/TERT1 cells, the MTT assay was the single most sensitive readout in case of cisplatin and gentamicin (Table 1). For these nephrotoxins, a decrease in MTT reduction occurred in absence of cell death or disintegration of the cell layer as detected by xCELLigence and TEER measurements. Since the MTT assay quantifies mitochondrial reductase activity, this finding likely mirrors the mitochondrial dysfunction reported as proximal events in cisplatin (Zsengeller et al. 2012) and gentamicin (Sepand et al. 2016) nephrotoxicity.

In case of zoledronate, MTT reduction and xCELLigence assay were equally sensitive suggesting that in this case the decrease in MTT reduction is due to cell death. In general, cellular impedance measurements using the xCELLigence system turned out to be not a particularly sensitive readout in our approach but nonetheless delivered unique insight into the kinetics of cytotoxicity by allowing for real-time measurements. For example, we were able to demonstrate that zoledronate-induced cytotoxicity is not only concentration- but also time-dependent, thereby suggesting that it is the cumulative dose over time that eventually elicits cell death. The latter stands in contrast to the results obtained for tacrolimus, which caused immediate cell death after minutes of exposure at $100 \mu \mathrm{M}$ but had no effect at $50 \mu \mathrm{M}$ and below, even when the cells were repeatedly challenged with the compound for 14 days. Consequently, real-time impedance measurements can provide some evidence on the type of toxicity, whether it is likely caused by exceeding a tolerable concentration ( $c_{\max }$ driven) or by cumulative exposure over time (AUC driven).

However, while the xCELLigence measurements failed to reveal alterations in the monolayer integrity apart from cell death, the quantification of TEER showed transient or possibly even persistent increases in monolayer resistance for many of the compounds tested but most prominently for cyclosporine A and tacrolimus which, with the exception of $100 \mu \mathrm{M}$ tacrolimus, had no effect on cell viability and impedance measurements. Consistent with previous publications (Aschauer et al. 2015b; Wilmes et al. 2014), non-treated RPTEC/TERT1 cells developed a stable TEER value of $120-140 \Omega \times \mathrm{cm}^{2}$ in the present study. When compared to other cell lines, e.g., intestinal carcinoma Caco-2 cells (Srinivasan et al. 2015), TEER in RPTEC/TERT1 cells is rather low, thus suggestive of the "leakiness" of 


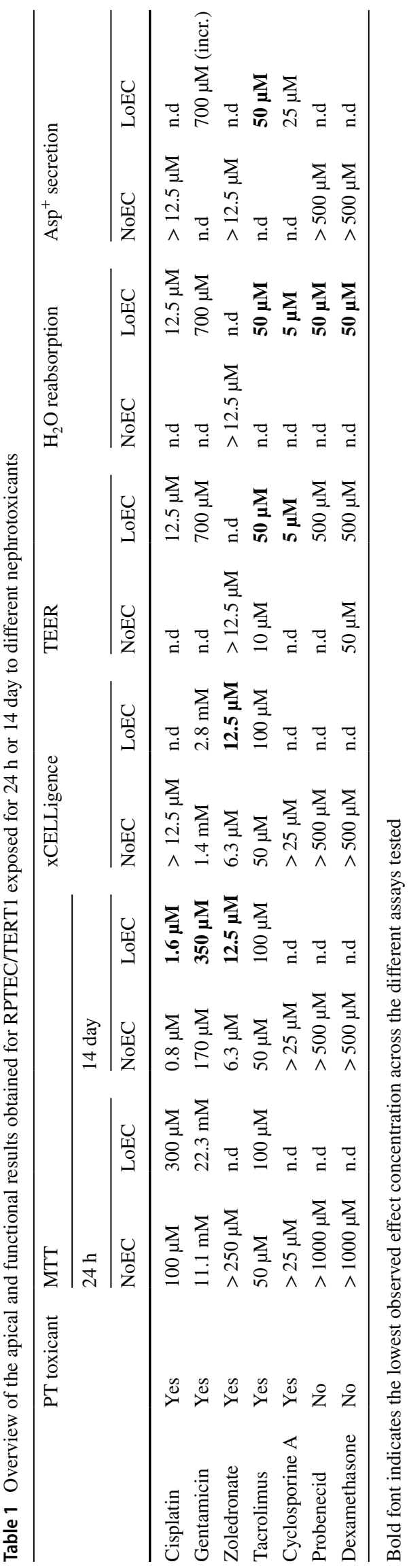

the monolayer. A transient increase in TEER in response to a toxic challenge was described previously (Aschauer et al. 2015b) and although the underlying mechanism is not fully understood it most likely involves modifications of tight junctions (Wilmes et al. 2014). A "tightening" of the monolayer, as measured by TEER, would also suggest a concomitantly decreased water permeability, as was demonstrated (Figs. 3b, 4a). Indeed, increased TEER and reduced water transport for cyclosporine $\mathrm{A}$ were reported in RPTEC/TERT1 cells earlier and involved a downregulation of the tight junction protein claudin-2, which was identified as a paracellular water channel (Wilmes et al. 2014). The findings reported here suggest that an impairment of water transport is a more general response towards cellular damage and therefore is likely shared by many, however, not all nephrotoxicants. As demonstrated, water transport by RPTEC/TERT1 cells is driven by the osmotic gradient built by the $\mathrm{Na}^{+} / \mathrm{K}^{+}$-ATPase for which multiple prerequisites must be fulfilled. Water transport requires at least integrity of the cell layer, functional transporters and high metabolic rates to fuel the $\mathrm{Na}^{+} / \mathrm{K}^{+}$-ATPase. It is probably because of this integration of multiple parameters that water transport proved a sensitive readout to detect toxicity.

Remarkably, the RPTEC/TERT1 monolayer fully recovered from the strong effects of cyclosporine A and tacrolimus on water transport within 10 days after compound removal, a fact that nicely reflects the reversibility of acute calcineurin inhibitor-induced nephrotoxicity observed in vivo (Naesens et al. 2009). Recovery from gentamicin and especially from the genotoxic cisplatin was less pronounced, thereby indicating sustained damage to the RPTEC/TERT1 cells. The fact that high concentrations of probenecid $(500 \mu \mathrm{M}$ exceeding the clinical $c_{\max }$ tenfold (Selen et al. 1982)), also reduced water transport and increased TEER, demonstrated that presumably non-nephrotoxic compounds can demonstrate offtarget effects when tested at sufficiently high concentrations. A somewhat controversial observation is the fact that a near linear decrease in water transport over time together with the diffusion-like permeation of $\mathrm{Asp}^{+}$after 7 days was observed with $500 \mu \mathrm{M}$ dexamethasone. The latter would suggest that the compound rendered the RPTEC/TERT1 monolayer permeable for small molecules like water and $\mathrm{Asp}^{+}$, however, in absence of a decrease in TEER, which in fact was slightly elevated. However, as has already been discussed in the case of probenecid, these effects are most likely due to the high concentration of $500 \mu \mathrm{M}$ dexamethasone that was applied, which exceeded the clinical $\mathrm{c}_{\max }$ by 50 -fold (Wenting-Van Wijk et al. 1999). Most likely clinically relevant concentrations would not show these effects, as indeed $50 \mu \mathrm{M}$ dexamethasone did not show an effect on TEER and only a limited effect on water permeability.

Similar to water transport, quantification of cation secretion using $\mathrm{Asp}^{+}$showed the most dramatic reductions for 
cyclosporine A and tacrolimus since both almost abolished cation secretion after a 7-day exposure. Whether this inhibition is due to a direct effect of cyclosporine A on either OCT or MATE transporters is unclear since such interaction is unknown at present. However, cyclosporine $\mathrm{A}$ is a potent inhibitor of P-gp and MRP2 (Morrissey et al. 2013) which at least share some substrates with MATEs, e.g., the chemotherapeutic agent topotecan (Morrissey et al. 2013). In contrast to cyclosporine A and tacrolimus, gentamicin significantly increased $\mathrm{Asp}^{+}$secretion after 7-day exposure. Since OCTs and MATEs transport both, $\mathrm{Asp}^{+}$and gentamicin (Gai et al. 2016), the latter effect might well be explained by an induction of OCT and MATE expression or activity induced by the high concentrations of gentamicin $(700 \mu \mathrm{M})$ used.

While we could successfully show the existence of a cation secretion axis requiring polarized OCT and MATE expression, we were unable to demonstrate functional anion secretion. Indeed a gene expression analysis revealed absence of OAT1-3, while MRP1-5 and the transporters required for cation secretion were clearly detected. Although another study (Aschauer et al. 2015a) reported OAT1 and OAT3 expression in RPTEC/TERT1 cells based on wholegenome expression data and western blots, functional anion secretion was not observed. Without diminishing the many functional benefits of the RPTEC/TERT1 cell line, the lack of functional OATs is a significant shortcoming. Similarly, the other recently established ciPTEC also lacked OAT1 and OAT3 expression (Wilmer et al. 2010). The present finding on RPTEC/TERT1 cells as well as the reports on ciPTECs might suggest that loss of OAT function could be a general artifact of in vitro culture of RPTECs caused by a yet unknown mechanism. However, since many well-established nephrotoxins are either substrates for OCTs or OATs (Morrissey et al. 2013), expression of both transporter classes is of key importance to obtain a comprehensive proximal tubule model. Nevertheless, the functional cation secretion present in RPTEC/TERT1 cells renders the cell line highly suitable to study drug-drug interactions occurring on this transport axis. Moreover, our recently established 3D cultivation model for RPTEC/TERT1 cells showed induction of many transporters including OATs (Secker et al. 2018) thus highlighting the promising prospects of RPTEC/TERT1 cells for nephrotoxicity testing.

In conclusion, we demonstrated that functional readouts using RPTEC/TERT1 cells add valuable information to standard cytotoxicity measurements. Interestingly, water reabsorption was particularly affected by cyclosporine A and tacrolimus, two nephrotoxins that did not affect cell viability. A promising approach to improve the prediction of nephrotoxicity using in vitro models would therefore combine classical endpoints with functional readouts. Especially the fact that TEER measurements as well as quantification of water and xenobiotic transport can be performed on line without termination of the experiment, renders the combination of these experiments with other readouts such as transcriptomics or proteomics approaches an attractive approach to detect the nephrotoxic potential of xenobiotics and therefore offer advanced opportunities to be used within pharmaceutical toxicity testing.

\section{Material and methods}

\section{Chemicals and solutions}

Cyclosporine A was purchased from Selleckchem (\#S2286) and New England Biolabs (\#9973). Tacrolimus was from Selleckchem (\#S5003) and Alfa Aesar (\#J63571). Zoledronic acid (\#Z5744) was from ENZO Life Sciences. Cisplatin (\#P4394), gentamicin (\#G1264), dexamethasone (\#D4902) and probenecid (\#P8761) were from Sigma-Aldrich.

\section{Cell culture}

RPTEC/TERT1 cells were obtained from Evercyte $\mathrm{GmbH}$ (Vienna, Austria). Cells were cultured in a 1-to-1 mixture of DMEM and Ham's F-12 nutrient mix (Thermo Fisher) with $5 \mathrm{mM}$ D-glucose final, supplemented with $2 \mathrm{mM}$ GlutaMAX, $5 \mu \mathrm{g} / \mathrm{ml}$ insulin (Sigma, \#I1882), $5 \mu \mathrm{g} / \mathrm{ml}$ transferrin (Sigma, \#T2252), $5 \mathrm{ng} / \mathrm{ml}$ sodium selenite (Sigma, \#S5261), $100 \mathrm{U} / \mathrm{ml}$ penicillin and $100 \mu \mathrm{g} / \mathrm{ml}$ streptomycin, $10 \mathrm{ng} / \mathrm{ml}$ EGF (Sigma, \#E9644) and $36 \mathrm{ng} / \mathrm{ml}$ hydrocortisone (Sigma, \#H0888). Cells were subcultured after establishing a contact-inhibited monolayer and reseeded at 30\% density when used on plastic plates or $100 \%$ density for Transwell permeable supports (Corning, polyester membrane, $0.4 \mu \mathrm{m}$ pore size). RPTEC/TERT1 cells were grown for at least 14 days before initiation of experiments with medium renewal every 2-3 days.

\section{Cell viability}

RPTEC/TERT1 cells were cultured on standard tissue culture plates for 16 days followed by exposure to compounds for either $24 \mathrm{~h}$ or 14 days with treatment renewal every $48 \mathrm{~h}$. Subsequently, treatment was exchanged for fresh medium containing $0.5 \mathrm{mg} / \mathrm{ml}$ MTT followed by incubation for $45 \mathrm{~min}$ at $37{ }^{\circ} \mathrm{C}, 5 \% \mathrm{CO} 2$. Cells were lysed using $95 \%$ isopropanol, $5 \%$ formic acid. Formazan absorption was measured at $550 \mathrm{~nm}$ using a Tecan M200Pro microplate reader. Absorption obtained for dead cells (treated with $0.1 \%$ Triton $\mathrm{X}-100$ ) was subtracted from all other values and viability was calculated relative to non-treated controls and is given as percent. 


\section{xCELLigence assay}

If not otherwise indicated, RPTEC/TERT1 cells were seeded on E-plates 96 (ACEA Biosciences Inc., San Diego, CA, USA) at 30\% density and placed into the RTCA SP instrument (Roche Diagnostics, Mannheim, Germany). After a growth and maturation period of at least 14 days, cells were treated with compounds or solvent control (0.5\% DMSO) or left non-treated. Cellular impedance was measured in intervals of $5 \mathrm{~min}$ for a total of 14 days. Treatment was renewed on Mondays, Wednesdays, and Fridays. Cell indices obtained for treated cells were normalized to non-treated cells and are given as percent.

\section{Transepithelial electrical resistance (TEER)}

RPTEC/TERT1 cells were seeded on 12-well trans-well permeable supports (Corning, \#3460). TEER was quantified manually using a Millicell-ERS (Millipore). TEER measurements were performed approximately 5-6 $\mathrm{h}$ after medium or treatment renewal on Mondays, Wednesdays, and Fridays.

\section{Water transport}

Medium from apical and basolateral compartments was collected during medium or treatment renewal and quantified using an analytical scale. To analyze compound-induced effects, water transport was normalized to control treated (0.5\% DMSO) cells and is given as percent.

\section{Quantitative real-time PCR (qPCR)}

Total RNA was isolated from RPTEC/TERT1 cells cultured on 6-well Transwell permeable inserts for 24 days using peqGOLD TriFast (VWR) according to manufacturer's protocol. Human kidney total RNA from a 70 year old Caucasian woman was purchased from life technologies (Product \#AM7967; Lot \#1,745,517). cDNA was synthesized from $1 \mu \mathrm{g}$ RNA using the cDNA-Synthesis Kit H Plus (VWR). qPCRs were performed using the KAPA SYBR FAST qPCR Master Mix (VWR) on a CFX Connect real-time system (Bio-Rad) according to manufacturer's protocol. Cq values obtained for genes of interest were normalized to the mean of Cq values obtained for the reference genes HPRT1, $\beta$ actin and RPL13A and are given as fold of this mean value. Gene-specific primer pairs used for amplification are given in Table S1. Specificity of all primers was confirmed by PCR product sequencing.

\section{Transport of fluorescent probes}

Vectorial transport of 4-Di-1-ASP (Asp ${ }^{+}$, Molecular Probes, \#D288) and Lucifer Yellow (LY, Sigma, \#L0259) was analyzed after addition of $12.5 \mu \mathrm{M}$ to either the apical of basolateral compartment. Fluorescence was quantified in $50 \mu \mathrm{l}$ aliquots taken from both compartments after $0,4,18$, 26, 41 and $47 \mathrm{~h}$ at $485 \mathrm{~nm}$ excitation, $590 \mathrm{~nm}$ emission for $\mathrm{Asp}^{+}$or excitation $428 \mathrm{~nm}$, emission $540 \mathrm{~nm}$ for LY. Fluorescence intensity was normalized to values obtained at $0 \mathrm{~h}$ for the compartment where the probe was added. To account for water transport while quantifying compound-induced effect on $\mathrm{Asp}^{+}$transport, fluorescence obtained for the apical compartment at the final timepoint ( $47 \mathrm{~h}$ ) was multiplied by the amount of medium present at this timepoint.

\section{Statistical analysis}

Unless indicated otherwise data are presented as mean \pm SEM. Sample size $(n)$ indicates the number of independent experiments performed. Statistical analysis was determined using GraphPad Prism Version 5.04 (La Jolla, CA, USA) using statistical tests as indicated in figure legends.

\section{References}

Aschauer L, Carta G, Vogelsang N, Schlatter E, Jennings P (2015a) Expression of xenobiotic transporters in the human renal proximal tubule cell line RPTEC/TERT1. Toxicol In Vitro 30(1 Pt A):95105. https://doi.org/10.1016/j.tiv.2014.12.003

Aschauer L, Limonciel A, Wilmes A et al (2015b) Application of RPTEC/TERT1 cells for investigation of repeat dose nephrotoxicity: a transcriptomic study. Toxicol In Vitro 30(1 Pt A):106-16. https://doi.org/10.1016/j.tiv.2014.10.005

Asphahani F, Zhang M (2007) Cellular impedance biosensors for drug screening and toxin detection. Analyst 132(9):835-841. https:// doi.org/10.1039/b704513a

Duff T, Carter S, Feldman G et al (2002) Transepithelial resistance and inulin permeability as endpoints in in vitro nephrotoxicity testing. Altern Lab Anim 30(Suppl 2):53-59

Gai Z, Visentin M, Hiller C et al (2016) Organic cation transporter 2 overexpression may confer an increased risk of gentamicininduced nephrotoxicity. Antimicrob Agents Chemother 60(9):5573-5580. https://doi.org/10.1128/AAC.00907-16

Hall AM, Unwin RJ (2007) The not so 'mighty chondrion': emergence of renal diseases due to mitochondrial dysfunction. Nephron Physiol 105(1):p1-10. https://doi.org/10.1159/000096860

Hausherr V, van Thriel C, Krug A, Leist M, Schobel N (2014) Impairment of glutamate signaling in mouse central nervous system neurons in vitro by tri-ortho-cresyl phosphate at noncytotoxic concentrations. Toxicol Sci 142(1):274-284. https://doi.org/10.1093/ toxsci/kfu 174

Jenkinson SE, Chung GW, van Loon E, Bakar NS, Dalzell AM, Brown CD (2012) The limitations of renal epithelial cell line HK-2 as a model of drug transporter expression and function in the proximal tubule. Pflugers Arch 464(6):601-611. https://doi.org/10.1007/ s00424-012-1163-2

Lepist EI, Ray AS (2016) Renal transporter-mediated drug-drug interactions: are they clinically relevant? J Clin Pharmacol 56(Suppl 7):S73-81. https://doi.org/10.1002/jcph.735 
Lin Z, Will Y (2012) Evaluation of drugs with specific organ toxicities in organ-specific cell lines. Toxicol Sci 126(1):114-127. https:// doi.org/10.1093/toxsci/kfr339

Loboz KK, Shenfield GM (2005) Drug combinations and impaired renal function-the 'triple whammy'. Br J Clin Pharmacol 59(2):239-243. https://doi.org/10.1111/j.0306-5251.2004.2188.x

Masereeuw R, Moons MM, Toomey BH, Russel FG, Miller DS (1999) Active lucifer yellow secretion in renal proximal tubule: evidence for organic anion transport system crossover. J Pharmacol Exp Ther 289(2):1104-1111

Miller RP, Tadagavadi RK, Ramesh G, Reeves WB (2010) Mechanisms of Cisplatin nephrotoxicity. Toxins (Basel) 2(11):2490-2518. https://doi.org/10.3390/toxins2112490

Morrissey KM, Stocker SL, Wittwer MB, Xu L, Giacomini KM (2013) Renal transporters in drug development. Annu Rev Pharmacol Toxicol 53:503-529. https://doi.org/10.1146/annurev-pharmtox011112-140317

Naesens M, Kuypers DR, Sarwal M (2009) Calcineurin inhibitor nephrotoxicity. Clin J Am Soc Nephrol 4(2):481-508. https://doi. org/10.2215/CJN.04800908

Paueksakon P, Fogo AB (2017) Drug-induced nephropathies. Histopathology 70(1):94-108. https://doi.org/10.1111/his.13064

Pazhayattil GS, Shirali AC (2014) Drug-induced impairment of renal function. Int J Nephrol Renovasc Dis 7:457-468. https://doi. org/10.2147/IJNRD.S39747

Perazella MA, Markowitz GS (2008) Bisphosphonate nephrotoxicity. Kidney Int 74(11):1385-1393. https://doi.org/10.1038/ ki.2008.356

Pfaller W, Gstraunthaler G (1998) Nephrotoxicity testing in vitro-what we know and what we need to know. Environ Health Perspect 106(Suppl 2):559-569

Puri S, Folias AE, Hebrok M (2015) Plasticity and dedifferentiation within the pancreas: development, homeostasis, and disease. Cell Stem Cell 16(1):18-31. https://doi.org/10.1016/j. stem.2014.11.001

Quiros Y, Vicente-Vicente L, Morales AI, Lopez-Novoa JM, LopezHernandez FJ (2011) An integrative overview on the mechanisms underlying the renal tubular cytotoxicity of gentamicin. Toxicol Sci 119(2):245-256. https://doi.org/10.1093/toxsci/kfq267

Sauzay C, White-Koning M, Hennebelle I et al (2016) Inhibition of OCT2, MATE1 and MATE2-K as a possible mechanism of drug interaction between pazopanib and cisplatin. Pharmacol Res 110:89-95. https://doi.org/10.1016/j.phrs.2016.05.012

Secker PF, Luks L, Schlichenmaier N, Dietrich DR (2018) RPTEC/ TERT1 cells form highly differentiated tubules when cultured in a 3D matrix. Altex 35(2):223-234. https://doi.org/10.14573/altex .1710181

Selen A, Amidon GL, Welling PG (1982) Pharmacokinetics of probenecid following oral doses to human volunteers. J Pharm Sci 71(11):1238-1242

Sepand MR, Ghahremani MH, Razavi-Azarkhiavi K et al (2016) Ellagic acid confers protection against gentamicin-induced oxidative damage, mitochondrial dysfunction and apoptosis-related nephrotoxicity. J Pharm Pharmacol 68(9):1222-1232. https://doi. org/10.1111/jphp.12589

Sirenko O, Grimm FA, Ryan KR et al (2017) In vitro cardiotoxicity assessment of environmental chemicals using an organotypic human induced pluripotent stem cell-derived model. Toxicol Appl Pharmacol 322:60-74. https://doi.org/10.1016/j.taap.2017.02.020

Srinivasan B, Kolli AR, Esch MB, Abaci HE, Shuler ML, Hickman JJ (2015) TEER measurement techniques for in vitro barrier model systems. J Lab Autom 20(2):107-126. https://doi. org/10.1177/2211068214561025

Tiong HY, Huang P, Xiong S, Li Y, Vathsala A, Zink D (2014) Druginduced nephrotoxicity: clinical impact and preclinical in vitro models. Mol Pharm 11(7):1933-1948. https://doi.org/10.1021/ mp400720w

Waring MJ, Arrowsmith J, Leach AR et al (2015) An analysis of the attrition of drug candidates from four major pharmaceutical companies. Nat Rev Drug Discov 14(7):475-486. https://doi. org/10.1038/nrd4609

Wenting-Van Wijk MJ, Blankenstein MA, Lafeber FP, Bijlsma JW (1999) Relation of plasma dexamethasone to clinical response. Clin Exp Rheumatol 17(3):305-312

Wieser M, Stadler G, Jennings P et al (2008) hTERT alone immortalizes epithelial cells of renal proximal tubules without changing their functional characteristics. Am J Physiol Renal Physiol 295(5):F1365-F1375. https://doi.org/10.1152/ajprenal.90405 .2008

Wilmer MJ, Saleem MA, Masereeuw R et al (2010) Novel conditionally immortalized human proximal tubule cell line expressing functional influx and efflux transporters. Cell Tissue Res 339(2):449-457. https://doi.org/10.1007/s00441-009-0882-y

Wilmes A, Limonciel A, Aschauer L et al (2013) Application of integrated transcriptomic, proteomic and metabolomic profiling for the delineation of mechanisms of drug induced cell stress. J Proteomics 79:180-194. https://doi.org/10.1016/j.jprot.2012.11.022

Wilmes A, Aschauer L, Limonciel A, Pfaller W, Jennings P (2014) Evidence for a role of claudin 2 as a proximal tubular stress responsive paracellular water channel. Toxicol Appl Pharmacol 279(2):163-172. https://doi.org/10.1016/j.taap.2014.05.013

Wilmes A, Bielow C, Ranninger C, et al. (2015) Mechanism of cisplatin proximal tubule toxicity revealed by integrating transcriptomics, proteomics, metabolomics and biokinetics. Toxicol In Vitro 30(1 Pt A):117-27. https://doi.org/10.1016/j.tiv.2014.10.006

Zsengeller ZK, Ellezian L, Brown D et al (2012) Cisplatin nephrotoxicity involves mitochondrial i njury with impaired tubular mitochondrial enzyme activity. J Histochem Cytochem 60(7):521-529. https://doi.org/10.1369/0022155412446227 